\title{
Multimarket Contact and Intensity of Competition: Evidence from an Airline Merger
}

\author{
Volodymyr Bilotkach
}

Published online: 1 December 2010

(C) The Author(s) 2010. This article is published with open access at Springerlink.com

\begin{abstract}
This paper examines the relationship between multimarket contact (MMC) and the intensity of competition. We take advantage of a recent merger, which altered the extent of MMC throughout the US airline industry, to understand the nature of MMC's impact on the airlines' frequency of service. Evidence that non-price effects of MMC are a part of the longer-term industry equilibrium is not robust. However, we observe that following the merger the market players started taking the degree of MMC into account in making their frequency decisions in line with the 'mutual forbearance' hypothesis; however, the effect showed signs of diminishing over time. Our results have implications for merger evaluation in industries where consolidation may lead to a higher extent of multimarket contact.
\end{abstract}

Keywords Airline industry $\cdot$ Mergers $\cdot$ Multimarket contact $\cdot$ Product quality

JEL Classification D43 $\cdot$ L13 $\cdot$ L40 $\cdot$ L93

\section{Introduction}

Understanding the factors that affect the intensity of competition between firms is a fundamental issue in industrial organization. It is customary for researchers to identify low prices as the indicator of intense competition in the industry, and high prices as either a manifestation of market power, or evidence of tacit collusion. At the same time, both price and non-price product characteristics (especially product quality) are

\footnotetext{
V. Bilotkach $(\varangle)$

Department of Economics, University of California, 3151, Social Science Plaza,

Irvine, CA 92697, USA

e-mail:vbilotka@uci.edu
} 
used by the firms as weapons in the fight for market share with the ultimate goal of securing market power.

Multimarket contact (MMC) occupies a conspicuous place in the list of factors that allegedly facilitate tacit collusion (and, more generally, 'softer' competition) in imperfectly competitive markets. The idea of mutual forbearance, whereby a firm will be inclined not to compete aggressively in a given market for fear of retaliation in other markets where it competes with the same firms, has been around for decades, yet it remained outside of the realm of rigorous theories of imperfectly competitive markets until Bernheim and Whinston (1990) study.

Empirical research on the role of multimarket contact in softening competition has mostly focused on the MMC-price relationship. Also, the higher degree of multimarket contact that follows increasing-concentration events in an industry was previously suggested to foster collusive behavior (Focarelli and Panetta 2003; Kim and Singal 1993; Singal 1996).

Our study is the first one to evaluate whether mergers that lead to increased MMC can soften competition in non-price product characteristics. This question is of nontrivial importance, as extensive multimarket contact is present in a number of important and highly visible industries (e.g., banking, restaurants, hotels, and retail).

We take advantage of a merger between America West Airlines and US Airwaysan event that increased the extent of multimarket contact in the US airline industry-to examine the potential effect of mutual forbearance on the airlines' choice of frequency of service. Frequency of service is a non-price product characteristic, which directly affects the passengers' full cost of travel. ${ }^{1}$ With higher frequency of service, an average customer is more likely to find a flight that is closer to his preferred departure time, diminishing the expected disutility of schedule delay, and lowering the total price of the trip (airfare plus value of travel time). We thus hypothesize that softer competition will arise via the airlines' choice of lower frequency of service in markets with a higher degree of MMC. Considering previous studies that suggest that consolidation events can alter firms' incentives to collude, we hypothesize that the merger could have provided the market participants with an incentive to soften competition, which would alter the way MMC is taken into account by the market participants when choosing frequency of service.

We use the data on non-stop flight frequencies throughout the US airline industry for the two years before and after the merger. We employ the difference-in-differences identification strategy to account for the general trends in the industry over this time period; carrier- and market-specific heterogeneities are accounted for with the airlinemarket fixed effects model. We use three measures of multimarket contact, including two new ones in addition to using a measure found in the previous literature.

Data analysis suggests that the association between MMC and flight frequency changed following the merger. This effect is most pronounced with the airlinemarket specific (rather than the more conventional market-specific) measures of MMC. Our data tell the following story: After the event, which increased industry-wide concentration and the extent of multimarket contact, the airlines across the industry

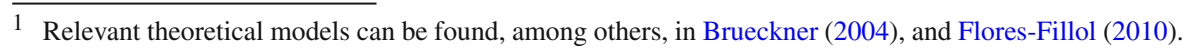


attempted to soften competition in a way that is consistent with the mutual forbearance hypothesis. In the long run, however, it appears that this new arrangement had only limited success. More generally, we can learn the following from our analysis: First, multimarket contact can influence firms' choices of non-price product characteristics. Second, rather than being a part of the equilibrium industry structure, this impact may be precipitated by an exogenous change in the level of MMC. Finally, we suggest that mergers that have a significant industry-wide effect on the extent of MMC may produce industry-wide strategic shifts in the choice of non-price product characteristics.

\section{Related Literature}

Empirical studies of multimarket contact have focused on its effect on prices in various industries. Pilloff (1999) and Focarelli and Panetta (2003) examine the issue in the context of the banking industry. Jans and Rosenbaum (1997) study the multimarket contact of cement producers. Busse (2000) evaluates the effect of MMC on the telecommunications markets. Fernandez and Marin (1998) look at the hotel industry. An earlier study by Feinberg (1985) provides an analysis of the mutual forbearance hypothesis throughout various industries (focusing on the effects of multimarket exposure on price-cost margins rather than on prices), and finds more support for the hypothesis in the firm than in the industry-level data.

Price effects of the multimarket contact in the airline industry have been studied by Evans and Kessides (1994) and Singal (1996). The only available analysis of the impact of MMC on non-price product characteristics (Prince and Simon 2009) also looks at the airline industry, examining the impact on flight delays and cancellations, and discovering the presumed effect. Prince and Simon analyze the impact of MMC on frequency, and they fail to find any significant relationship; however, their analysis examined the issue of multimarket contact over a cross-section of markets. Our paper makes use of the panel data structure; this allows us to incorporate the effect of an exogenous consolidation event.

The following empirical studies of the airline industry are also related to this paper. Pai (2010) offers a general examination of determinants of aircraft size and frequency choices in the US airline industry. Bilotkach et al. (2010), focusing primarily on the relationship between the frequency choice and distance, offer an analysis of the frequency choice by the airlines on a set of European markets. Richard (2003) examines the welfare effects of a hypothetical merger between American Airlines and United Airlines for Chicago-originating routes, focusing on the carriers' choice of prices and frequency. Borenstein (1990) and Kim and Singal (1993) examine the price and market power effects of the 1980s wave of airline mergers. Clougherty (2002) suggests that US airline mergers improve the international competitiveness of US carriers. Mazzeo (2003) establishes the relationship between airline competition and service quality (measured by the airlines' on-time performance). As a side note, our study is among 
the first ones to examine the effects of the recent large mergers in the US airline industry. $^{2}$

\section{US Airways-America West Merger}

USAir (later changed to US Airways) is the name that Allegheny Airlines adopted after expanding throughout the 1980s, acquiring Pacific Southwest Airlines and Piedmont Airlines in 1987. The carrier has grown throughout the 1990s, developing hubs in Baltimore, Philadelphia, Charlotte, and Pittsburgh, as well as establishing itself as the biggest airline at Ronald Reagan National Airport in Washington, D.C.

US Airways was hit very hard by the events of September 11, 2001, holding on until August 11, 2002, before entering the Chap. 11 bankruptcy protection. ${ }^{3}$ The carrier was able to emerge from Chap. 11 in 2003, only to be forced there again on September 12, 2004 , by rising fuel prices and deadlocked negotiations with unionized labor. At that time, the airline's share of domestic passengers was about $7 \%$, down from over $10 \%$ before September 11, 2001.

America West Airlines was one of the carriers that emerged after the deregulation of the 1970s and early 1980s. The airline started flying on August 1, 1983, out of hubs in Phoenix and Las Vegas. America West concentrated its operations in the Western (more specifically, Southwestern) part of the US (in the 1990s the airline established a smaller hub in Columbus, Ohio, which it dismantled in 2003); it also operated coastto-coast services, as well as flights to Mexico, Canada, and Hawaii. While an important player in the Southwestern part of the US airline market, America West remained a relatively small airline; its market share never exceeded $4 \%$ in terms of the number of passengers carried (this was America West Airlines' share just before the merger with US Airways).

The two carriers, while operating non-overlapping networks, were no strangers to each other: They were part of a code-sharing agreement, which also included United Airlines. Soon after US Airways went into Chap. 11 proceedings for the second time in 2004, America West suggested buying the carrier, and keeping US Airways name. The merger did not meet much resistance from the regulators: The two airlines directly competed on only half a dozen routes with non-stop flights, and their combined market share in the US domestic market was only around $11 \%$. The merger closed on September 27, 2005, but negotiations with the labor unions and merging the airlines' reservation systems was put off until a later date. ${ }^{4}$

The America West operating certificate was merged into that of US Airways (meaning America West Airlines "officially" ceased to exist) only two years after the merger

\footnotetext{
2 In addition to the merger reviewed in this paper, Delta Air Lines acquired Northwest Airlines in October of 2008. On October 1, 2010, United Airlines completed its merger with Continental Airlines, creating the world's largest air carrier.

3 According to the US Bankruptcy Code, a business can file for bankruptcy protection under either Chap. 7 (implying cessation of operations) or Chap. 11 (implying reorganization ultimately to stay in business).

4 As an example, US Airways' pilots and flight attendants had on average been with the airline for a longer time than had America West's workers (since US Airways is an older airline). So, merging the carriers' seniority lists proved to be a complicated matter.
} 
was closed; nevertheless, the carriers' decision-making (as far as price setting and scheduling is concerned) has been joint since the merger closing date. From September 27, 2005, until the merger of the operating certificates, all America West flights have been announced as "US Airways flights operated by America West Airlines".

The America West-US Airways merger provides a "clean" event for examining the effects of multimarket contact for the following reasons: First, unlike the merger wave in the 1980s, this was a stand-alone event. Second, the merger had repercussions for the entire airline industry, as networks of the merger participants were complementary and covered most of the US market. Third, unlike with the American Airlines' acquisition of TWA in April 2001, no catastrophic events occurred in the US airline industry around the time of the merger that is examined in this paper. We thus should be able to employ a relatively straightforward difference-in-differences estimation strategy to account for the time trends and carrier-specific effect and identify the effect of the merger on the MMC-frequency relationship in the US airline industry.

\section{Data}

\subsection{Sample}

The main dataset that we will use in our analysis is the T-100 Segment, collected monthly by the US Department of Transportation. The dataset is downloadable from the department's web-site and contains, at the airline-airport-pair-market level, information on the number of seats offered, passengers carried, and flights performed by each airline in each market where the carrier offers non-stop passenger service. We treat markets as non-directional ${ }^{5}$ (e.g., Los Angeles-Denver flights are lumped with Denver-Los Angeles).

We confined our analysis to two years before the US Airways-America West merger (2003 and 2004) and two years after the event (2006 and 2007). Further, we only used information for February and July of each of the above years. Traditionally, February is the month when demand for the air travel is at its trough, while in July it is at its peak. Also, the airlines tend to revise their schedules semi-annually (so-called Winter and Summer schedules); so, choosing only two months of the year, we will not lose much information as far as the airlines' choice of frequency is concerned.

We included only the routes within the contiguous United States (thereby excluding flights to/from/within Alaska and Hawaii, as well as the flights to/from Puerto Rico). We required that each airport on the route be located within a Metropolitan Statistical Area, ${ }^{6}$ and that a route be served with scheduled commercial passenger airline flights at least 20 times a month in February and 21 times in July. ${ }^{7}$ Regional carriers that provide services for the network airlines were merged with the corresponding network

\footnotetext{
5 Frequency (unlike, for instance, price) is usually not chosen directionally. Bilotkach et al. (2010) also drop directionality in their study.

6 This will allow us easily to merge the traffic data with the MSA-level demographics.

7 Since the markets are not directional, this is roundtrip frequency, so we effectively included all the routes between the airports that are located within the US Census Bureau's Metropolitan Statistical Areas, on which about one flight per three days was scheduled.
} 
carriers. ${ }^{8}$ For the eight month-year combinations that we included into our dataset, we ended up with over 16,000 unique airline-airport-pair-market level observations, representing a total of 1,926 unique airport-pair markets. Of those, 623 airport-pair markets (corresponding to 6,854 observations) featured non-stop services by more than one carrier in at least one of the months covered by our data.

The last restriction that we imposed on our sample involved excluding all markets in which both US Airways and America West directly competed with non-stop services prior to the merger. There were only six such markets, resulting in loss of merely seventy observations.

\subsection{Variables}

As the dependent variable, we use the natural logarithm of monthly frequency at the airline-route level.

The literature offers various measures of MMC, and there is no commonly accepted way of constructing this variable. Route-specific measures are more popular in the airline industry studies. In this study we will, among others, use the average multimarket contact measure that is identical to the one that was used by Evans and Kessides (1994); however, our focus will be on the airline-market specific measures that we construct ourselves.

Specifically, we will use two airline-market level measures of multimarket contact: one that captures the 'absolute' extent of multimarket contact (denoted AMMC), and the other one that measures MMC 'relative' to the airline's total operations (we will use notation RMMC for this one).

The first measure will count the number of markets in which the airline competes with non-stop services with the other carrier(s) that it encounters on a given route. Specifically, for each pair of airlines $(i$ and $j$ ), we count the number of airport-pair markets in which the two carriers both provide non-stop service (denote this number as $n_{i j}$ ). Then, the extent of MMC for the airline $i$ in market $k$ will be calculated as:

$$
\mathrm{AMMC}_{i}^{k}=\sum_{j \neq i} I_{i j}^{k} n_{i j},
$$

where $I_{i j}^{k}$ is simply the indicator of whether the two airlines both offer non-stop service in the given airport-pair market; the summation is done over the population of the airlines.

To calculate the second measure of airline-market level MMC, we will compute the total number of flights that carrier $i$ performs in markets in which it faces competition

\footnotetext{
8 In the US market, some of the commercial passenger services (particularly on thinner markets) are performed by the so-called regional carriers, operating as agents of the major airlines. Those can be either independent companies (SkyWest, Atlantic Southeast), or fully-owned subsidiaries of network carriers (American Eagle). Several such airlines perform services for more than one major airline (e.g., SkyWest flies as a Delta, United, and Midwest agent). Where a regional carrier was known to perform the flights for more than one major airline, classification was made according to the hub airport to/from which the service was performed; airlines that share hub airports have not been found to share a regional carrier.
} 
with the airline $j$ with non-stop service (we will denote this number as $f_{i j}$ ). Specifically:

$$
f_{i j}=\sum_{k} I_{i j}^{k} f_{i}^{k}
$$

Summation in (2) is done over all the airport-pair markets. Then, if the total number of flights that an airline $i$ performs over its entire network is $F_{i}$, the "relative" measure of MMC for the airline $i$ in market $k$ will be:

$$
\mathrm{RMMC}_{i}^{k}=\frac{1}{F_{i}} \sum_{j \neq i} I_{i j}^{k} f_{i j}
$$

Both measures will be equal to zero for the monopoly airport-pair markets. Note also that RMMC is not theoretically bounded by one from above, as flights overlapping with several airlines are counted more than once in the numerator.

The market-specific measure of multimarket conduct we will use (this measure was also used by Evans and Kessides 1994) is the average of the above-described measures of "absolute" multimarket contact for a given market, or:

$$
\operatorname{AvgMMC}^{k}=\left(N^{k}\right)^{-1} * \sum_{i} I_{i}^{k} * \mathrm{AMMC}_{i}^{k}
$$

where $N^{k}$ is the number of unique carriers operating on the market $k$, and $I_{i}^{k}$ is the indicator of the airline $i$ 's presence on the market. Note that mean of AvgMMC will be the same as the mean of AMMC.

Table 1a includes descriptive statistics for frequency and MMC measures. It is evident that the US Airways-America West merger resulted in an appreciable increase in the average MMC. This is especially remarkable in light of the fact that the combined market share of the two airlines was only around $11 \%$. This seemingly disproportionate increase in the extent of multimarket contact is explained by the fact that the carriers' networks did not overlap. For instance, a carrier (e.g., Continental Airlines) that competed with US Airways in 20 markets and with America West in 30 other markets before the merger will after the merger find itself competing with the "new" US Airways in 50 markets. Then, for the markets that had been Continental-US Airways or Continental-America West duopolies before the merger (and remained Continental-US Airways duopolies after the merger), our AMMC would increase from 20 to 50 (note that on the duopoly routes AMMC takes on the same value for both airlines). However, if ten of those markets overlapped, Continental Airlines would find itself competing in 40 markets with the "new" US Airways. In the markets that had before the merger been triopolies with Continental Airlines, US Airways, and America West present, the value of AMMC for Continental Airlines would decrease from 50 to 40 (other things equal).

Also visible from Table 1a is the general trend toward lower frequency of service over time. This is actually just a reflection of a longer term tendency for using 


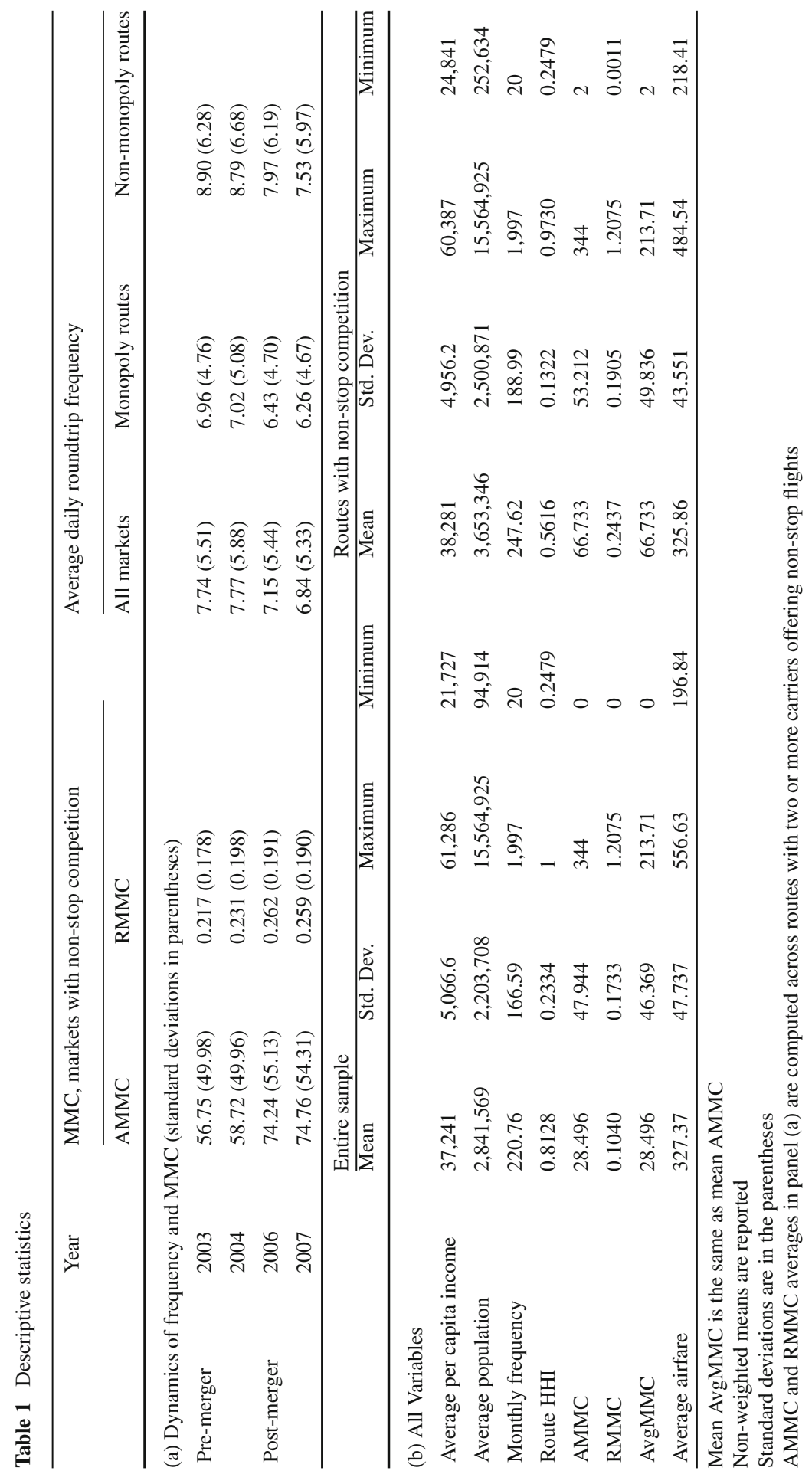


smaller aircraft in the US domestic markets, unrelated to the US Airways-America West merger. Note however that the frequency trend is more pronounced on the non-monopoly routes.

Our estimation technique of choice will be the airline-airport-pair-market fixed effects. This model is appropriate in light of the fact that most participants ${ }^{9}$ in the US domestic market operate hub-and-spoke networks (e.g., Delta Air Lines channels a lot of its traffic via its hub at Atlanta Hartsfield Airport). Thus, decisions on frequency on the hub-spoke routes (such as Delta Air Lines' New Orleans to Atlanta flight) will be driven not only by the demand in this particular market, but also (and sometimes predominantly) by the demand in a multitude of the spoke-to-spoke markets to which the airline's passengers will be connecting via the hub (many of the passengers on New Orleans-Atlanta flight will be traveling elsewhere via Atlanta, and Delta has to take this into account when deciding how many flights to schedule between these two cities). The airline-airport-pair-market fixed effects specification captures the heterogeneities associated with the structure of the airlines' networks.

To account for the market-specific heterogeneities that are not captured by the fixed effects, we will use the following control variables: Market size will be captured by the geometric averages of the endpoints' per capita income and population (at the respective MSA level). ${ }^{10}$ Route-level passenger Herfindhal-Hirschmann index (at the airport-pair market level) will be used to account for market concentration. Time (month-year, month, and year) dummy variables will control for the corresponding heterogeneities. ${ }^{11}$ Since the airlines' frequency decisions may depend on the price that carriers can command, we include a measure of airfares. We have used the airportlevel average airfares for originating passengers, reported by the US Department of Transportation (DOT). DOT collects a quarterly 10\% sample of actual airline itineraries, known as databank DB1B. This sample includes various itineraries-one-way and roundtrip, non-stop and connecting flights. Then, DOT uses DB1B dataset for the US domestic market to compute average fares for trips that originate at various airports. This is what we will refer to as the airport-level average airfares. We have taken the average of this fare for the two airports (note that our frequency data is non-directional), and lagged it one year to avoid the otherwise inevitable endogeneity problem.

The Herfindhal-Hirschmann index (HHI) is potentially endogenous. To correct for this problem, we have used the number of competitors at the airport-pair-market level as an instrument. This instrument (note that it is negatively correlated with HHI) is moderately strong - with the correlation coefficient around - 0.6. One can legitimately argue that this instrument might not completely resolve the problem of correlation with

\footnotetext{
9 Southwest Airlines relies more on direct point-to-point services, while still technically operating several smaller hubs.

10 We need to acknowledge here that within-variation in these variables, especially in population, is not substantial over the time period that we considered, leading to potential inefficiency of the estimates. However, excluding these variables from the specifications would likely lead to model misspecifications, with far more serious results than mere inefficiency.

11 Due to the obvious multicollinearity issue, we have only been able to include a limited number of such dummy variables. Specifically, we used dummy variables for month of July, years 2004 and 2006, and the February-2007 and July-2004 interactions.
} 
the error term; this is true to the extent that unobserved shocks that lead to entry or exit also change the competing airlines' frequency of service. At the very least, the likelihood of the unobserved shocks that affect a given airline's frequency of service also affecting HHI is much higher than that of the same shocks causing market entry or exit. Similar results to those reported here (with a loss of the number of observations and goodness of fit) were obtained using the lagged number of competitors as the instrument for HHI. Note also that our study is the first one to take account of the potential endogeneity of HHI in airline frequency regressions.

Table $1 \mathrm{~b}$ presents the descriptive statistics for the main variables we use. Since our data analysis will focus in large part on the sub-sample of routes with non-stop competition, descriptive statistics for this set of markets are reported separately.

\section{Analysis and Results}

\subsection{Hypotheses and Methodology}

Our aim is to examine how multimarket contact is taken into account by the market players in determining the frequency of service. The anti-competitive effects of multimarket contact on the non-price product characteristics can be manifested through the lower frequency of service with the higher extent of MMC, other things equal. As discussed above, lower frequency increases the total cost of travel for passengers by increasing schedule delay.

We will perform the analysis in two ways. First, we will not separate the potential impact of the merger, effectively evaluating whether MMC affects frequency in the longer-term industry equilibrium. Second, we will postulate that the US AirwaysAmerica West merger, having increased the extent of MMC, could have had a structural effect on the way that MMC affects the airlines' choice of frequency.

Making such a distinction will allow us to make conclusions as to the origins of the effect of multimarket contact. If we determine that the merger was the primary force behind any observed association between the MMC and softer competition, we will conclude that changes in the industry structure can have a 'structural' impact on the market players' strategies. Any estimated effect of MMC in the analysis that assumes that the merger had no impact will give us a general indication of the effect that multimarket contact has on the airlines' non-price competition strategies in what could be considered a longer-term industry equilibrium.

To sum up, the postulated association between the MMC and the airlines' frequency of service is that we expect a greater extent of MMC to be associated with a lower frequency of service.

If this association is a part of the longer-term industry equilibrium, we will observe it through the corresponding sign of the coefficients on measures of MMC. A study of the effect of the merger on MMC-frequency relationship following the merger will require a difference-in-differences identification strategy. We will need to account for general market and time effects, and try to ensure that the post-merger effect of MMC on frequency is over and above any 'usual' effect of multimarket contact. 
We will approach the problem in two ways: First, since the increase in MMC following the merger should not have changed the airlines' choices on the monopoly markets beyond the general industry trend, any post-merger versus pre-merger difference in frequency choices on the non-monopoly markets that also experienced a change in the level of MMC (i.e., markets served by either of the merger participants) should be more significant than the same comparison for the monopoly routes. The corresponding specification will be:

$$
\begin{aligned}
\log (\text { Frequency })= & \beta_{1} I_{\text {non-monopoly }}+\beta_{2} I_{\text {post-merger }}+\beta_{3} I_{\text {USHPMarkets }} \\
& +\beta_{4} I_{\text {post-merger }} * I_{\text {USHPMarkets }} \\
& +\beta_{5} I_{\text {non-monopoly }} * I_{\text {USHPMarkets }} \\
& +\beta_{6} I_{\text {non-monopoly }} * I_{\text {post-merger }} \\
& +\beta_{7} I_{\text {post-merger }} * I_{\text {non-monopoly }} * I_{\text {USHPMarkets }} \\
& + \text { controls }+ \text { error. }
\end{aligned}
$$

Here, $I_{\text {USHPMarkets }}$ stands for the indicator variable for the markets that were served by either US Airways or America West Airlines; ${ }^{12}$ the remaining notations are selfexplanatory. Then, the key variable will be the post-merger-non-monopoly-routeUSHP interaction. If our hypothesis of the structural impact of the merger on the MMC-frequency relationship is true, the corresponding coefficient $\left(\beta_{7}\right)$ will be negative.

This approach, however, does not take advantage of our measures of MMC; also, any changes in the airlines' competition strategies that are not associated with the change in MMC and result in lower frequency will yield observationally equivalent results. Our second approach will utilize our measures of multimarket contact at the expense of excluding monopoly airport-pair markets from the sample. Specifically, we will estimate the following regression:

$$
\begin{aligned}
& \log (\text { Frequency })=\gamma_{1} \mathrm{MMC}+\gamma_{2} I_{\text {post-merger }}+\gamma_{3} I_{\text {USHPMarkets }} \\
& +\gamma_{4} I_{\text {post-merger }} * I_{\text {USHPMarkets }}+\gamma_{5} \text { MMC } * I_{\text {USHPMarkets }} \\
& +\gamma_{6} I_{\text {post-merger }} * \mathrm{MMC} * I_{\mathrm{USHPM}} \text { arkets }+ \text { controls }+ \text { error, }
\end{aligned}
$$

where MMC is one of our measures of multimarket contact. The main variable is again the interaction between the post-merger indicator, the measure of multimarket contact, and the dummy for markets in which the merger participants operate. As before, if our hypothesis is true, the corresponding coefficient ( $\gamma_{6}$ this time) will be negative. Note that the specification that evaluates the effect of MMC unconditionally from the merger will include only MMC and the dummy variables for the merger and for the USHP markets, and exclude any of this variable's interactions with other regressors.

As noted above, we have estimated both market level and airline-market level fixed effects models; our focus however will be on the latter. We have used both GLS with

12 Recall that markets that were served by both US Airways and America West have been thrown out of the sample. 
cluster robust standard errors, ${ }^{13}$ and the instrumental variable technique (two-stage least squares, or 2SLS), using the number of competitors as the instrument for HHI. To examine the longer-run structural effect of the merger on the MMC-frequency relationship, we have rerun our specifications, restricting the sample in the following ways: First, we have excluded the first year after the merger (year 2006); second, we have only retained years 2003 and 2007 (2 years before and two years after the merger).

A usual robustness check of the difference-in-differences estimator involves incorrectly imposing the timing of the shock. If the effect is still observed when the timing of the shock is incorrect, one may suspect that the data analysis methodology is flawed. The main robustness check we will administer will involve artificially placing the merger between 2003-2004 and 2006-2007. This will redefine (rather, incorrectly define) the post-merger time period. Also, to check that our results are not driven by the non-linearity of the MMC-frequency relationship, we included both MMC and MMCsquared terms as independent variables in the regressions that evaluate the unconditional effect of MMC. The results are not reported here; however, MMC-squared was not significant in any of the 2SLS airline-market level fixed effects models.

\subsection{Results}

The estimation results are presented in the following tables: Table 2 reports the results of estimation (5); both market and airline-market fixed effects models are presented. Table 3 includes results for the markets with non-stop competition; here we only report the airline-market fixed effects specifications, making a distinction between GLS and 2SLS techniques in panels (a) and (b), respectively. Note that we also make a distinction between evaluating the effect of MMC on frequency unconditionally for the merger (i.e., as a part of the longer-term industry equilibrium), and examining whether the merger could have caused a structural shift in the market players' strategies. Table 4 reports results for the sub-samples excluding year 2006, as well as including only years 2003 and 2007. The robustness check imposing the artificial—and incorrect-merger dates is presented in Table 5.

The results of the market-level fixed effects model, reported in Table 2, indicate that following the merger, frequency of service on the non-monopolized markets decreased more significantly than on the monopolistic airport-pair routes. The size of this effect is small $(1.2 \%)$ and only marginally significant in market fixed effects model without IV, and strengthens in both magnitude (to about 4.3\%) and significance when HHI is instrumented for with the number of competitors. However, this effect does not carry over to a more realistic airline-market fixed effects model.

Evaluating the results for the markets with nonstop competition (Table 3), we see substantial qualitative differences between the GSL and the 2SLS specifications. Most strikingly, the evidence of the unconditional MMC-frequency relationship vanishes when we instrument for HHI. At the same time, the evidence of the hypothesized effect of the merger on the MMC-frequency relationship carries over to the instrumental var-

$\overline{13}$ We control for both across cross-section heteroscedasticity and within cross-section autocorrelation. 


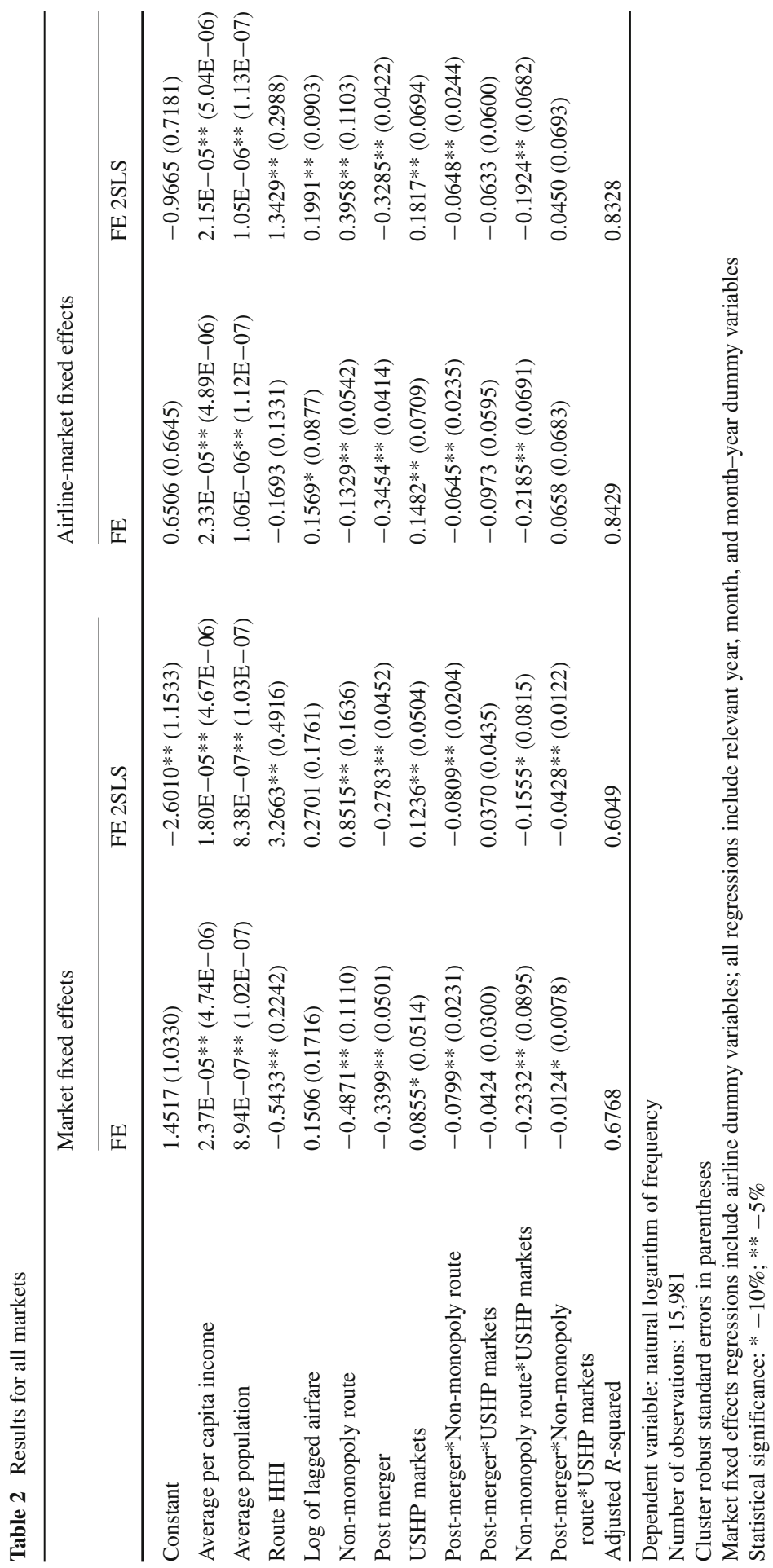




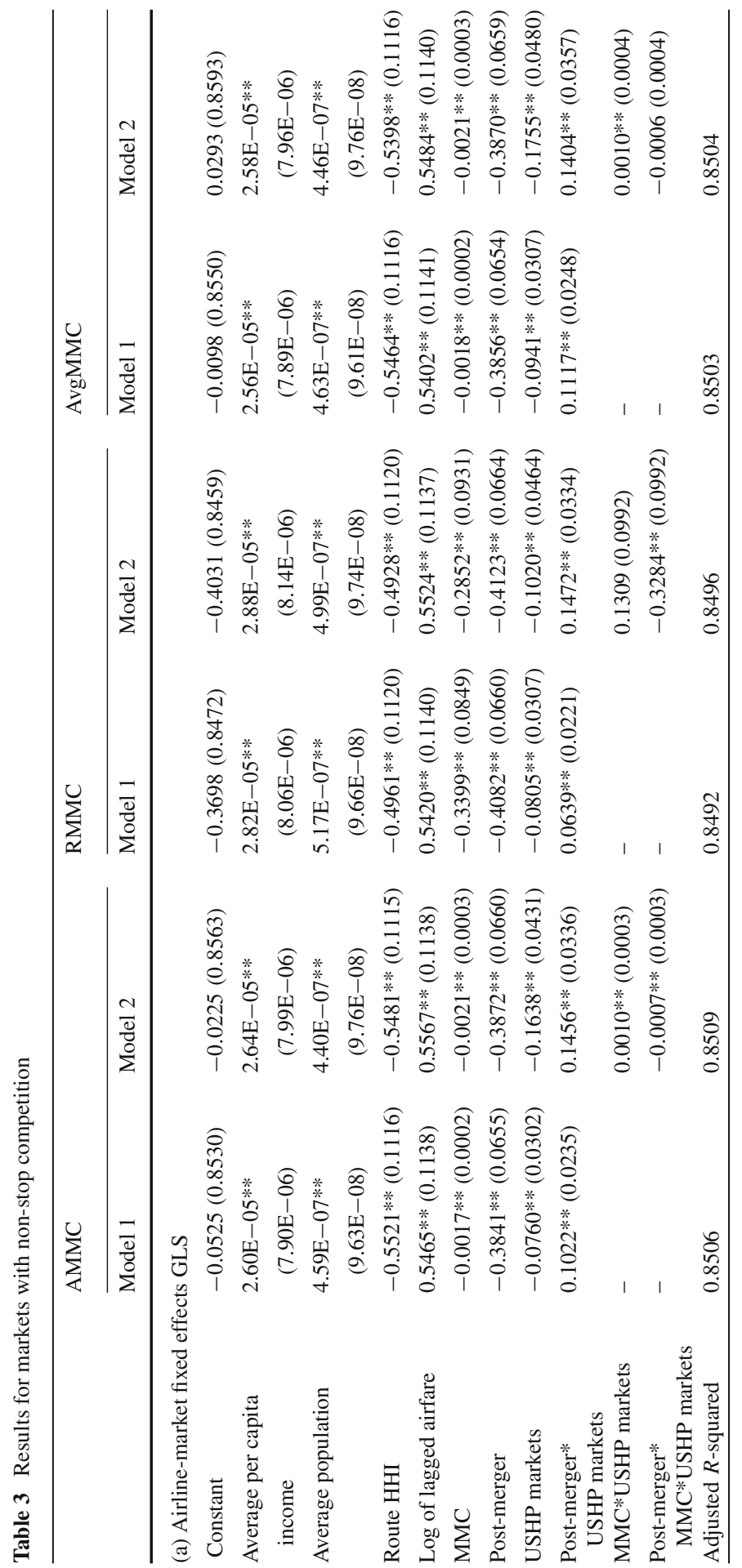




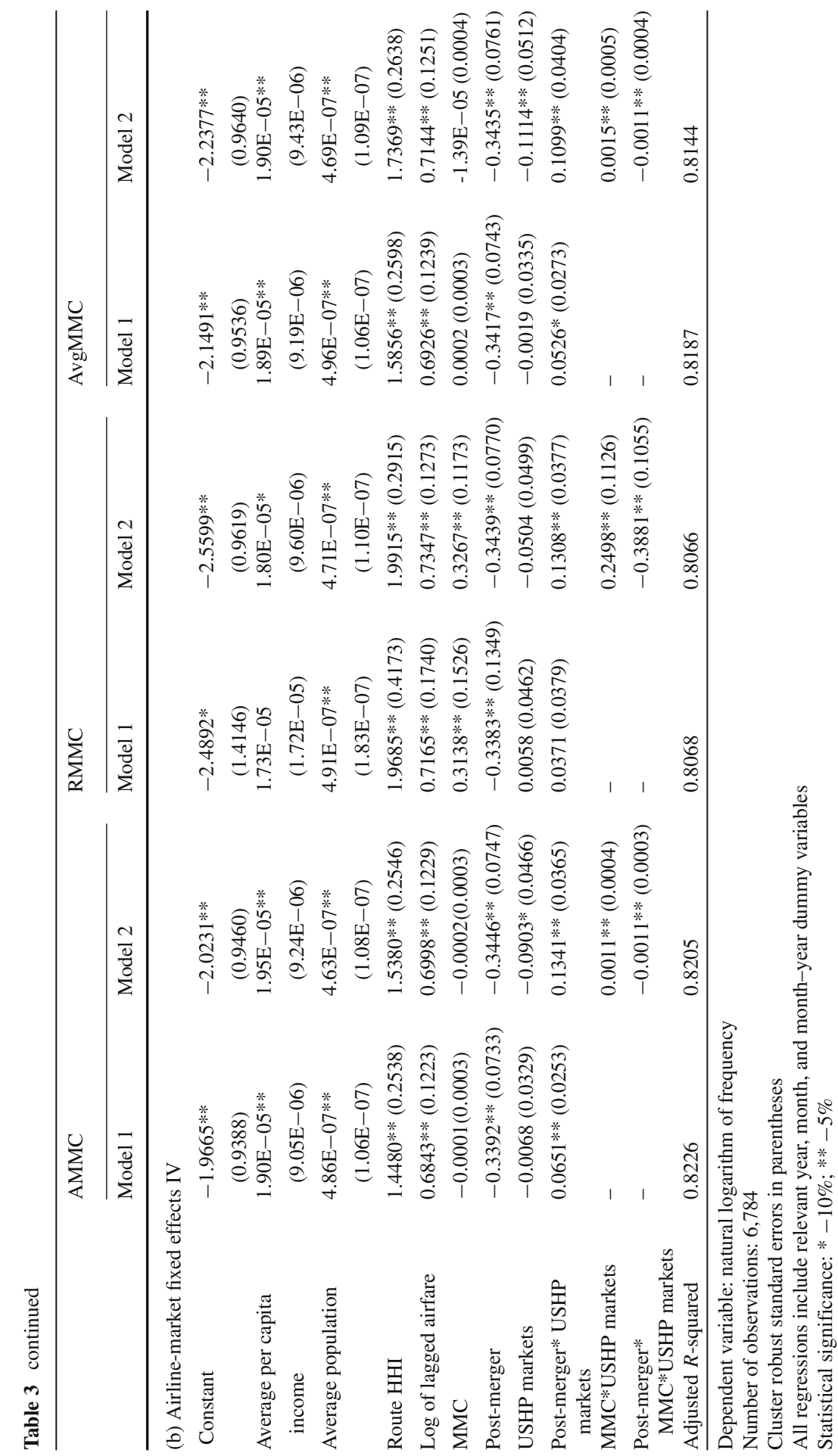




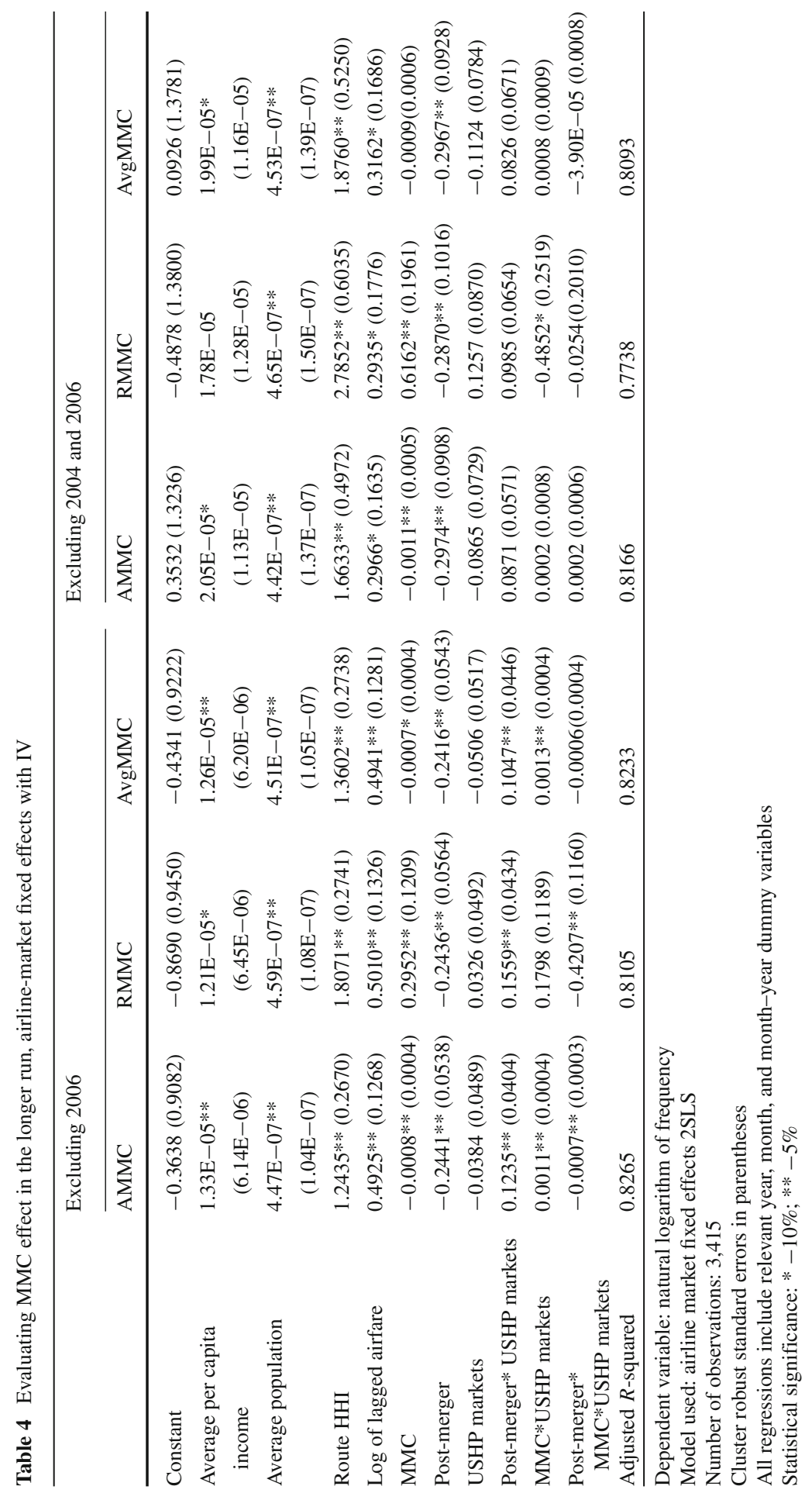




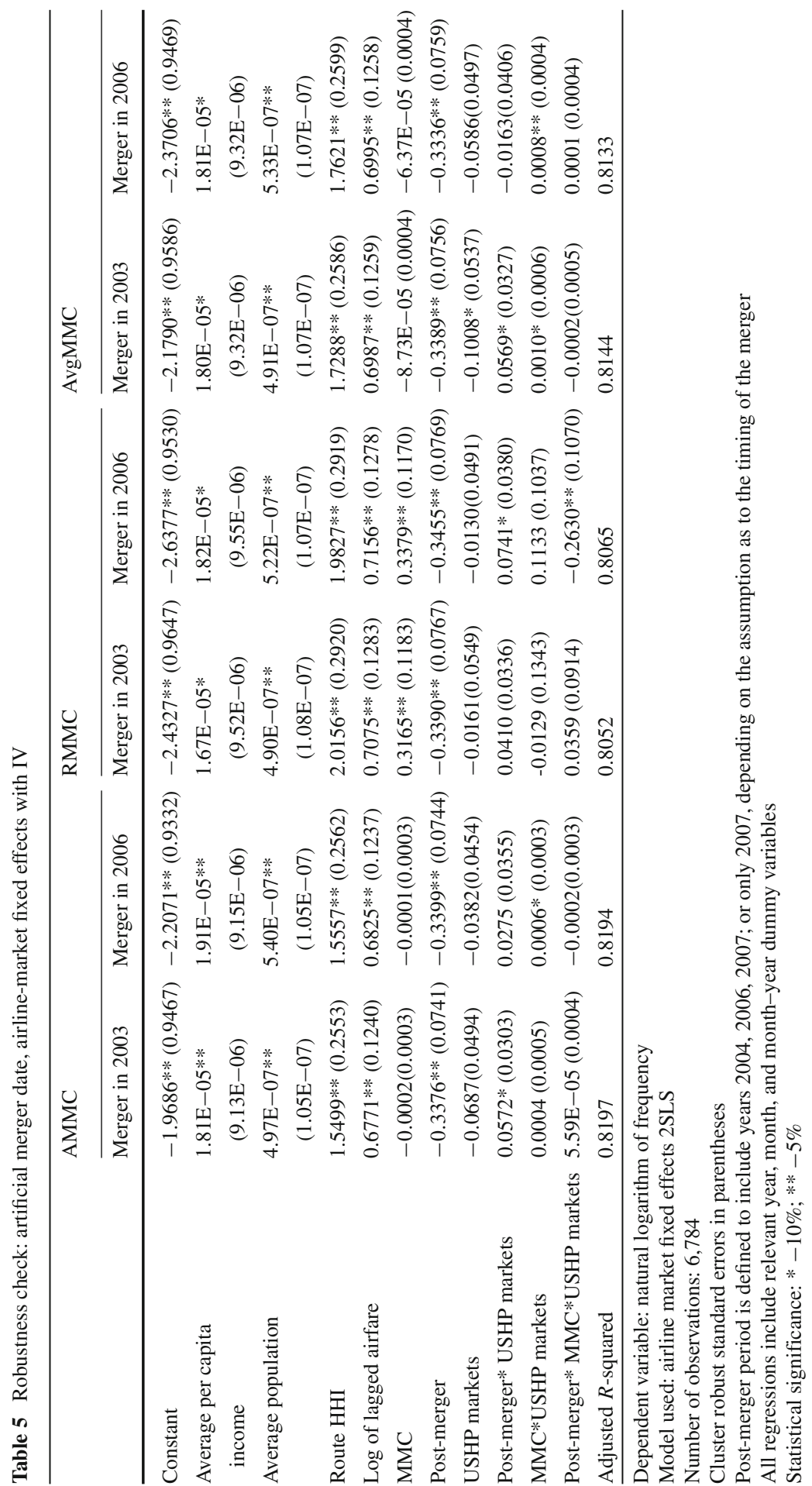


iable specifications. Note that this evidence is only robust for the airline-market level measures of multimarket contact. Numerically, the coefficient on the AMMC $\times$ PostMerger $\times$ USHPMarket interaction variable from the corresponding specification in Table $3 \mathrm{~b}$ suggests about a $7.3 \%$ decrease in frequency of service at the mean value of AMMC for the sub-sample of routes with the non-stop competition. ${ }^{14}$ Given the corresponding sub-sample mean frequency, this translates into 16 fewer flights per month. To put this into perspective, the average carrier in the affected markets cuts roughly two roundtrips per week (as opposed to what that carrier would have done absent the merger). The corresponding effect for RMMC is slightly larger-around a $9.5 \%$ reduction in frequency at the sub-sample mean. This translates into almost 21 fewer flights per month, or about 2.5 roundtrips per week.

The results presented in Table 4 show limited support for the supposition that the effect of the merger on the MMC-frequency relationship was long-lived. This appears consistent with the carriers' attempting to soften competition following an event that increased the extent of MMC throughout the industry; yet we can also say that this attempt was not especially successful, as the lack of evidence for the longer-term "strategic" shift following the merger suggests. The robustness checks that are reported in Table 5 demonstrate that (with only one exception) setting the merger date arbitrarily does not produce the previously detected effect of the merger on the MMC-frequency relationship.

Thus, we postulated that the US Airways-America West merger could have produced a change in MMC significant enough for the increase in multimarket contact to start affecting the airlines' frequency choices. We determined this to be true for the airline-market fixed effects specifications and the airline-market specific measures of MMC; evidence for the route-specific measure of multimarket contact is weaker. The structural effect of merger on the impact of MMC that we detect is actually consistent with the findings of previous studies of the price effects of multimarket contact (Focarelli and Panetta 2003; Kim and Singal 1993; Singal 1996).

In summary, the post-merger effect of MMC on frequency-the key non-price characteristic of airline services - has been to decrease it, thereby making travel less convenient for an average passenger, and effectively increasing the total price of the trip. Our results imply that the well-documented anti-competitive price effects of MMC may be compounded by the lower product quality, at least following an event that increases the extent of the multimarket contact. Moreover, since frequency of service is directly related to the total cost of travel for the passengers, we are effectively documenting the MMC-price effect, looking at it from a different angle.

The effect that we observed dissipates over time; this appears to be consistent with a not exceptionally successful attempt at softening the competition on the nonprice side of the product characteristics following a consolidation event, which has increased the extent of MMC throughout the industry. Finally, robustness checks that

\footnotetext{
14 To get this number, simply multiply the corresponding regression coefficient from Table $3 b$ by the average AMMC for the sub-sample of markets with non-stop competition, from Table 1b. Then, recall that the resulting number is the estimate of the difference in logarithm of frequency of service, which approximates percentage change.
} 
we implemented suggested that the observed effect is due to the merger, and cannot be considered random or explainable by general industry trends.

The control variables exhibit relatively stable behavior across specifications, with one notable exception. The effect of the measure of market concentration that we employ (the Herfindhal-Hirschmann index) reverses when we move from GLS to instrumental variables specifications. On the one hand, we can expect that the airlines' competition in frequency of service may lead to higher frequency of service in response to less market concentration, other things equal (e.g., Bilotkach et al. 2010). On the other hand, when some market participants increase their frequency of service, HHI will increase even if the competitors do not respond to this change in any way, implying a potential positive correlation between the two variables. Note that our study is the first one to recognize this endogeneity between frequency and market concentration. Other control variables exhibit expected behavior: frequency rises with per capita income, population, and airfares.

\section{Concluding Comments}

This paper takes advantage of a recent merger in the US airline industry to examine the effects of the multimarket contact on the market players' behavior from a new angle. Specifically, we examine the effects of MMC on frequency as the most notable non-price product characteristic of the airlines' services. Our study differs from most of the previous literature on the issue of multimarket contact, which looks at the price effects. We would like to learn whether the well-documented price effects are exacerbated on the product quality side, so that "mutual forbearance" leads not only to higher prices, but also to lower product quality. At the same time, our investigation is related to the studies of price effects of multimarket contact, since the measure of quality that we have chosen (frequency of service) directly affects the passengers' total price of travel, which includes the airfare and the value of travel time.

We examine the impact of MMC both unconditionally on the merger, and postulating that the merger, having changed the degree of the multimarket contact throughout the industry, could have served as a structural shock for the market participants, affecting the impact of multimarket contact on the airlines' choice of frequency. This suggestion is consistent with the literature that finds that mergers could have changed the nature of competition among market participants.

We did find that the US Airways-America West merger changed the way that the airlines take into account the extent of MMC when making strategic choices as to frequency of service. Specifically, following the merger, the greater extent of MMC became associated with a lower frequency (above and beyond the general industry trend for fewer flights). The documented effects show up more robustly in the specifications employing the airline-market specific measures of MMC, as compared to the regressions using a market-specific measure (the latter approach appears to be more popular in the literature).

Also, we found that the obtained effects are larger in magnitude immediately after the merger than when evaluated over a more extended time period. This pattern appears consistent with the attempt to use a greater extent of multimarket contact following 
the merger to reach an equilibrium involving softer competition, manifested in lower product quality (in particular, lower frequency). This serves as additional evidence of the "structural" shock that the merger had: It appears that in the longer term, the effect of MMC is weak (as also evidenced by the not robust unconditional effect on frequency), but an exogenous change in the extent of multimarket contact will affect the market participants' conduct.

We can learn the following from our analysis: First, multimarket contact can influence the firm's choices of non-price product characteristics. Second, rather than being a part of equilibrium industry structure, this impact may be precipitated by an exogenous change in the level of MMC. Finally, we suggest that mergers that have a significant industry-wide effect on the extent of MMC may produce industry-wide strategic (and not pro-competitive) shifts in the choice of non-price product characteristics. The list of industries in which a merger can have a large-scale effect on the extent of multimarket contact is potentially long (hotels, fast food restaurants, banking, retail, just to name a few-generally, any industry where competition is between the chains of stores); therefore, it will be possible and interesting to apply our methodology to other industries to gauge the general applicability of our results. If similar evidence to that presented here is collected for other markets, this may point to an additional effect that should be taken into consideration when evaluating proposed mergers and acquisitions.

Acknowledgments The author thanks Jan Brueckner, Jeffrey T. Prince, Claudio Piga, Steven Puller, seminar participants at San Francisco State University, KU Leuven, and Otto Beisheim Business School (WHU); as well as conference participants in Boston, Mannheim, and Atlanta for comments on earlier drafts. Two anonymous referees and Editor White provided invaluable suggestions and guidance.

Open Access This article is distributed under the terms of the Creative Commons Attribution Noncommercial License which permits any noncommercial use, distribution, and reproduction in any medium, provided the original author(s) and source are credited.

\section{References}

Bernheim, B. D., \& Whinston, M. D. (1990). Multimarket contact and collusive behavior. RAND Journal of Economics, 21, 1-26.

Bilotkach, V., Fageda, X., \& Flores-Fillol, R. (2010). Scheduled service versus personal transportation: The role of distance. Regional Science and Urban Economics, 40, 60-72.

Borenstein, S. (1990). Airline mergers, airport dominance, and market power. AER Papers and Proceedings, 80, 400-404.

Brueckner, J. (2004). Network structure and airline scheduling. Journal of Industrial Economics, 52, 291312.

Busse, M. R. (2000). Multimarket contact and price coordination in the cellular telephone industry. Journal of Economics and Management Strategy, 3, 287-320.

Clougherty, J. (2002). US domestic airline mergers: The neglected international determinants. International Journal of Industrial Organization, 20, 557-576.

Evans, W. N., \& Kessides, I. N. (1994). Living by the "Golden Rule": Multimarket contact in the U.S. Airline industry. The Quarterly Journal of Economics, 109, 341-366.

Feinberg, R. M. (1985). "Sales-at-Risk": A test of the mutual forbearance theory of conglomerate behavior. Journal of Business, 58, 225-241.

Fernandez, N., \& Marin, P. L. (1998). Market power and multimarket contact: Some evidence from the Spanish hotel industry. Journal of Industrial Economics, 46, 301-315.

Flores-Fillol, R. (2010). Congested hubs. Transportation Research Part B, 44, 358-370. 
Focarelli, D., \& Panetta, F. (2003). Are mergers beneficial to consumers? Evidence from the market for bank deposits. American Economic Review, 93, 1152-1172.

Jans, I., \& Rosenbaum, D. I. (1997). Multimarket contact and pricing: Evidence from the U.S. cement industry. International Journal of Industrial Organization, 15, 391-412.

Kim, E. H., \& Singal, V. (1993). Mergers and market power: Evidence from the airline industry. American Economic Review, 83, 549-569.

Mazzeo, M. (2003). Competition and service quality in the us airline industry. Review of Industrial Organization, 22, 275-296.

Pai, V. (2010). On the factors that affect airline flight frequency and aircraft size. Journal of Air Transport Management, 16, 169-177.

Pilloff, S. J. (1999). Multimarket contact in banking. Review of Industrial Organization, 14, $163-182$.

Prince, J., \& Simon, D. (2009). Multimarket contact and on-time performance in the U.S. airline industry. Academy of Management Journal, 52, 336-354.

Richard, O. (2003). Flight frequency and mergers in airline markets. International Journal of Industrial Organization, 21, 907-922.

Singal, V. (1996). Airline mergers and multimarket contact. Managerial and Decision Economics, 17, 559574. 